\title{
Differences in the intensity of physical activity during school days and weekends in Polish and Czech boys and girls
}

\author{
Karel Frömel', Michal Kudlacek ${ }^{1,2}$, Dorota Groffik ${ }^{3}$, Frantisek Chmelik ${ }^{1}$, Lukas Jakubec ${ }^{1}$ \\ ${ }^{1}$ Faculty of Physical Culture, Institute of Active Lifestyle, Center for Kinanthropology Research, Palacký University, \\ Olomouc, Czech Republic \\ ${ }^{2}$ Faculty of Physical Culture, Department of Recreation and Leisure Studies, Palacký University, Olomouc, Czech Republic \\ ${ }^{3}$ Department of Physical Education, Academy of Physical Education, Katowice, Poland
}

Frömel K, Kudlacek M, Groffik D, Chmelik F, Jakubec L. Differences in the intensity of physical activity during school days and weekends in Polish and Czech boys and girls. Ann Agric Environ Med. 2016; 23(2): 357-360. doi: 10.5604/12321966.1203905

\begin{abstract}
Introduction and objective. The physical, mental and social development that occurs in young people through physical activity (PA) is primarily through extracurricular activities. Family, peers and social environment, in addition to schools, interest groups and school sports, play a unique role during this developmental period. The objective of the study was to examine the differences in the intensity of PA during school days and weekends and the relationship between PA and physical inactivity (PI) during these days in Polish and Czech boys and girls.

Materials and methods. In total, there were 816 participants among whom 333 met the requirements of 8 hours of continuous recording of PA (ActiTrainer accelerometers) during at least one school and one weekend day.

Results. Boys and girls from both countries engaged in virtually the same amount of PA during school and weekend days, and participated in more PA at lower intensities on the weekends compared with school days.

Conclusions. This study surveyed important issues related to global public health, specifically for the school environment and school settings. The important and crucial relations with family were emphasized, which should increase the awareness and understanding of public health problems of this particular research sample. The results indicated that less time was spent in PI, but also that the largest amount of time during the weekends was spent in front of a screen.
\end{abstract}

\section{Key words}

active lifestyle, school environment, school setting, family, public health, monitoring, accelerometer

\section{INTRODUCTION}

Convincing evidence showing the positive effects of physical activity (PA) on a wide range of lifestyle determinants is constantly increasing. The benefits of PA are observed not only in the area of health care $[1,2,3]$, but also in the economic sector [4] and in school performance in the case of children and adolescents $[5,6]$.

The physical, mental and social development that occurs in young people through PA is primarily through extracurricular activities. Family, peers and social environment, in addition to schools, interest groups and school sports clubs play a unique role during this developmental period. For these individuals, $75-85 \%$ of PA takes place during their free time (outside school), and only $15-25 \%$ of PA is organized by the school $[7,8,9]$.

Despite a greater degree of free time during weekends, young people are less physically active on weekends compared with school days [10]. Reduced PA in young people during weekends has been demonstrated in both boys and girls $[10,11,12]$. Similar differences between working days and weekends have been found in children [13], adults [14, 15] and seniors [2]. Boys are more physically active than girls during both school and weekend days $[16,17,18]$. Most of the findings regarding lower PA during weekends have been

Address for correspondence: Michal Kudlacek, Faculty of Physical Culture, Department of Recreation and Leisure Studies, Palacký University Olomouc, Tr. Miru 117, 77111, Olomouc, Czech Republic

E-mail: michal.kudlacek@upol.cz

Received: 10 December 2013; accepted: 20 January 2015 based on the duration of the PA [10]. Fewer studies have focused on the differences in the intensity of the PA during school days and weekends [12]. The most critical day of the week for PA in adolescents in Poland, the Czech Republic and Slovakia is Sunday [19].

\section{OBJECTIVE}

The main objective of this study was to examine the differences in the intensity of PA during school days and weekends, and the relationship between PA and physical inactivity during these days in Polish and Czech girls and boys.

\section{MATERIALS AND METHOD}

The research was conducted at 14 secondary schools in the Czech Republic and 10 schools in Poland between January - June in 2013. In total, there were 816 participants among whom 333 met the requirements of 8 hours of continuous recording of PA during at least one school and one weekend day (Tab. 1). The research design and documentation were approved by the Ethical Committee of the Academy of Physical Education in Katowice, Poland, and the Faculty of Physical Culture at Palacky University in Olomouc in the Czech Republic.

The ActiTrainer ${ }^{\mathrm{TM}}$ accelerometer was used for PA monitoring. It recorded the participants' PA and heart rate every 15 seconds. Correlation values expressing the 
Table 1. Sample characteristics of groups

\begin{tabular}{|c|c|c|c|c|}
\hline \multirow{2}{*}{ Characteristics } & \multicolumn{2}{|c|}{$\begin{array}{c}\text { Boys } \\
(\mathrm{M} \pm \mathrm{SD})\end{array}$} & \multicolumn{2}{|c|}{$\begin{array}{c}\text { Girls } \\
(\mathrm{M} \pm \mathrm{SD})\end{array}$} \\
\hline & $\begin{array}{l}\text { Czech } \\
(\mathrm{n}=71)\end{array}$ & $\begin{array}{l}\text { Polish } \\
(\mathrm{n}=39)\end{array}$ & $\begin{array}{c}\text { Czech } \\
(n=165)\end{array}$ & $\begin{array}{l}\text { Polish } \\
(n=58)\end{array}$ \\
\hline Age (years) & $16.0 \pm 1.0$ & $16.5 \pm 0.7$ & $16.0 \pm 1.0$ & $17.7 \pm 0.5$ \\
\hline Weight (kg) & $67.0 \pm 11.5$ & $69.2 \pm 10.5$ & $57.9 \pm 7.5$ & $58.2 \pm 7.7$ \\
\hline Height (cm) & $177.5 \pm 7.1$ & $178.1 \pm 6.0$ & $167.3 \pm 6.1$ & $167.0 \pm 5.3$ \\
\hline BMI $\left(\mathrm{kg} \cdot \mathrm{m}^{-2}\right)$ & $21.2 \pm 3.2$ & $21.7 \pm 2.7$ & $20.7 \pm 2.5$ & $20.8 \pm 2.2$ \\
\hline RHR (count·min) & $58 \pm 6$ & $57 \pm 6$ & $61 \pm 7$ & $60 \pm 5$ \\
\hline $\begin{array}{l}\text { Steps (count·school } \\
\text { day.hour }\end{array}$ & $737 \pm 264$ & $642 \pm 288$ & $758 \pm 227$ & $686 \pm 265$ \\
\hline $\begin{array}{l}\text { Steps (count } \cdot \text { weekend } \\
\text { day } \text { hour }^{-1} \text { ) }\end{array}$ & $569 \pm 359$ & $601 \pm 444$ & $644 \pm 354$ & $653 \pm 357$ \\
\hline $\begin{array}{l}\text { PA (min·school } \\
\left.\text { day } \cdot \text { hour }^{-1}\right)\end{array}$ & $21.90 \pm 5.20$ & $21.22 \pm 5.87$ & $21.75 \pm 4.12$ & $20.24 \pm 4.71$ \\
\hline $\begin{array}{l}\text { PA (min } \bullet \text { weekend } \\
\left.\text { day } \cdot \text { hour }^{-1}\right)\end{array}$ & $21.82 \pm 9.71$ & $21.48 \pm 10.15$ & $22.67 \pm 7.29^{*}$ & $22.49 \pm 7.0^{*} 4$ \\
\hline 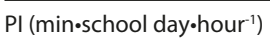 & $38.10 \pm 5.20$ & $38.78 \pm 5.87$ & $38.25 \pm 4.12$ & $39.76 \pm 4.71$ \\
\hline $\begin{array}{l}\mathrm{PI}(\min \cdot \text { weekend } \\
\left.\text { day } \cdot \text { hour }^{-1}\right)\end{array}$ & $38.18 \pm 9.71$ & $38.52 \pm 10.15$ & $37.33 \pm 7.29^{*}$ & $37.51 \pm 7.04^{*}$ \\
\hline
\end{tabular}

BMI - Body Mass Index; RHR - resting heart rate; $M$ - mean; $S D$ - standard deviation; PA physical activity; $\mathrm{PI}$ - physical inactivity; * $p<.05$ significant difference between school days and weekends

relationships between the number of actual and devicemeasured steps range from $0.96-0.97$ [20]. The participants' training in PA monitoring with an accelerometer, time recording, measuring morning resting heart rate and the course of the research process were always performed by the same research team. The participants used accelerometers during at least one school and one weekend day beginning in the morning (after their morning hygiene) and continuing throughout the whole day (except for showering and swimming) until immediately before their evening sleep hygiene. The accuracy of the cardiac frequency monitoring was checked after their arrival at school using the Heart Rate Monitor Polar S610TM.

All of the participants received the following feedback after the research was concluded: time information about the duration of PA and inactivity, their caloric output, heart rate and number of steps. Further, they received information about their workload in METs and heart rate zones, along with comprehensible curves of daily caloric output and heart rate.

Monitoring and data processing. A special software programme, ActiTrainer09 [20], which is available in a Czechonly version (http://www.cfkr.eu), was used for data processing. Physical activity and inactivity were recorded in minutes. The PA intensity was recorded according to the heart rate from $30-100 \%$ of MHR in ten-percentage point increments and according to the METs in one-MET increments. A formula (kcals $/ \mathrm{min}=.0000191^{\star}$ counts $/$ minute ${ }^{\star}$ body mass in $\mathrm{kg}$, Actigraph, 2012 (https://help.theactigraph.com)) was used to convert 'counts' into METs. To determine the heart rate zone, a universal formula was used for calculating maximum heart rate $(\mathrm{MHR}=220$ - age). It should be noted for comparative reasons that this formula does not take into account girls' higher average heart rate. Stress zones (determined by the load) were divided by $10 \%$ of the MHR, in accordance with Edwards (1994) [20], and further classified as low (50-59.9\% of MHR; < 3 METs), moderate (60-79.9\% of MHR; 3-5.9 METs) and vigorous PA (80-100\% MHR; $\geq 6$ METs). Participants wearing the device at least 8 and at most 18 hours were included in the results of monitoring.

Data analysis. SPSS 19 and Statistica 9 were used to perform the statistical evaluations, including basic statistical characteristics, ANOVA (post-hoc Fisher LSD test), the Wilcoxon test, and also to determine the 'effect size' using $\omega^{2}[22,23]$. An $\omega^{2}$ with a value of. $01 \leq \omega^{2}<.06$ was considered to be a small effect size, an $\omega^{2}$ of. $06 \leq \omega^{2}<.14$ was considered to be a medium effect size, and an $\omega^{2} \geq .14$ was considered to be a large effect size.

\section{RESULTS}

Significant differences in PA between school days and weekends were recorded, particularly for low-intensity PA (Tab. 2). Boys and girls were more physically active at lower

Table 2. PA intensity in girls and boys during school days and weekend days

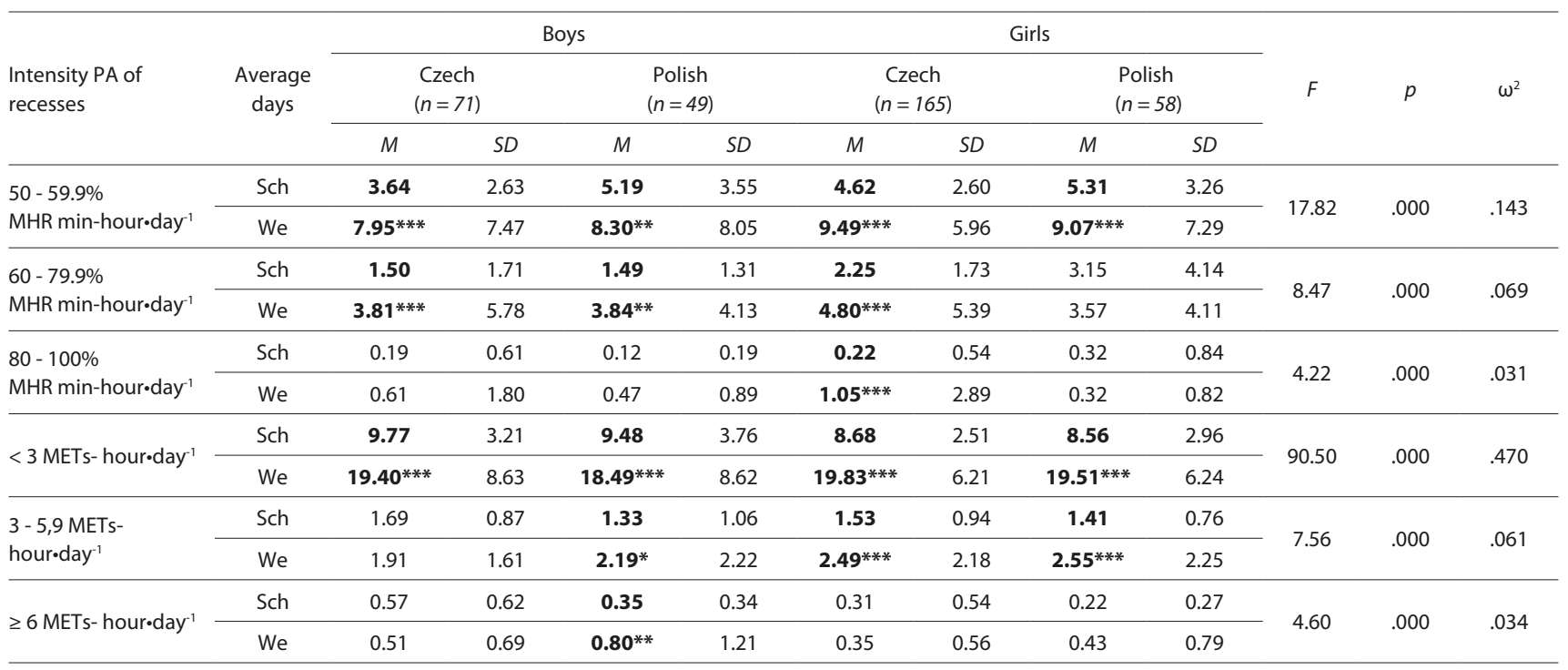

Sch - school day; We - weekend day; $M$ - mean; SD - standard deviation; F-ANOVA test; $\omega^{2}$ - coefficient effect size; $p<.05,{ }^{* *} p<.01,{ }^{* * * *} p<.001$ significant difference between school days and weekend days 
intensities (50-59.9\% MHR min-hour•day ${ }^{-1} ;<3$ METshour $\bullet$ day $^{-1}$ ) during weekends, compared with school days. An increased load of PA during weekends that was confirmed by the participants' heart rates and METs in PA was found only in Czech girls and Polish boys (60-79.9\% MHR minhour $\bullet d a y^{-1}$ and 3-5.9 METs-hour $\bullet$ day $\left.{ }^{-1}\right)$, but the low $\omega^{2}$ effect size suggests that these results should be interpreted with caution.

The differences found between daily PA during school days and weekend days based on subjective records of daily physical activities were in agreement with the differences found by monitoring PA (Tab. 1). However, there was a significant difference in the PI records, and a decrease in PI was observed during weekends for all groups. PA monitoring using accelerometers confirmed these differences in PI between school and weekend days only for girls, but these results were unlikely to have clinical significance (Fig. 1).

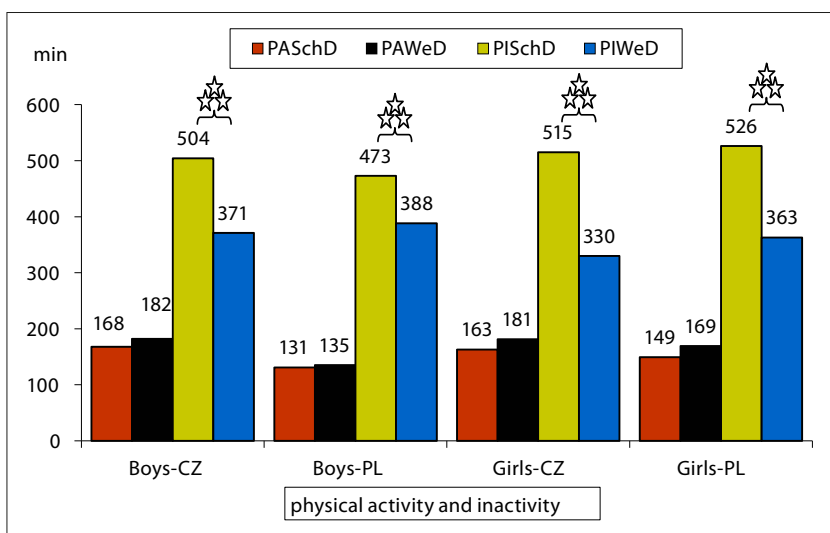

Figure 1. Average daily duration ( $\mathrm{min}$ ) of physical activity and inactivity reported in girls' $(n=377$ Czech, Polish $n=185)$ and boys' $(n=153$ Czech, Polish $n=101)$ records 解解 $\mathrm{p}<.001$

The largest proportion of PI during school days for young people obviously took place at school (Tab. 3). This PI was

Table 3. The structure of average daily physical inactivity (min) in girls and boys during school days and weekends

\begin{tabular}{|c|c|c|c|c|c|c|c|c|c|}
\hline \multirow{3}{*}{ Physical inactivity } & \multirow{3}{*}{$\begin{array}{l}\text { Average } \\
\text { days }\end{array}$} & \multicolumn{4}{|c|}{ Boys } & \multicolumn{4}{|c|}{ Girls } \\
\hline & & \multicolumn{2}{|c|}{$\begin{array}{l}\text { Czech } \\
(n=153)\end{array}$} & \multicolumn{2}{|c|}{$\begin{array}{l}\text { Polish } \\
(n=101)\end{array}$} & \multicolumn{2}{|c|}{$\begin{array}{c}\text { Czech } \\
(n=377)\end{array}$} & \multicolumn{2}{|c|}{$\begin{array}{l}\text { Polish } \\
(n=185)\end{array}$} \\
\hline & & $M$ & $S D$ & $M$ & $S D$ & $M$ & $S D$ & $M$ & $S D$ \\
\hline Sitting at school & Sch & 298 & 131 & 211 & 241 & 291 & 302 & 271 & 288 \\
\hline \multirow{2}{*}{$\begin{array}{l}\text { Sitting (lying) while } \\
\text { studying, fading, } \\
\text { playing, etc. }\end{array}$} & Sch & 38 & 44 & 108 & 123 & 52 & 46 & 89 & 88 \\
\hline & We & 43 & 61 & 50 & 83 & 64 & 74 & 69 & 82 \\
\hline \multirow{2}{*}{$\begin{array}{l}\text { Sitting (lying) at a } \\
\text { computer }\end{array}$} & Sch & 89 & 64 & 86 & 59 & 52 & 45 & 57 & 40 \\
\hline & We & 143 & 123 & 157 & 124 & 82 & 81 & 96 & 74 \\
\hline \multirow{2}{*}{$\begin{array}{l}\text { Sitting (lying) while } \\
\text { watching TV (screen) }\end{array}$} & Sch & 45 & 40 & 47 & 38 & 44 & 40 & 50 & 38 \\
\hline & We & 79 & 79 & 81 & 82 & 75 & 73 & 92 & 82 \\
\hline \multirow{2}{*}{$\begin{array}{l}\text { Sitting (lying) while } \\
\text { playing sports and at } \\
\text { cultural events }\end{array}$} & Sch & 17 & 38 & 20 & 41 & 27 & 51 & 23 & 49 \\
\hline & We & 26 & 67 & 23 & 59 & 33 & 72 & 26 & 60 \\
\hline \multirow{2}{*}{$\begin{array}{l}\text { Sitting (lying) at } \\
\text { conveyance }\end{array}$} & Sch & 33 & 40 & 26 & 33 & 46 & 42 & 35 & 35 \\
\hline & We & 29 & 57 & 22 & 51 & 37 & 62 & 31 & 47 \\
\hline \multirow{2}{*}{$\begin{array}{l}\text { Sitting in parks, } \\
\text { restaurants, etc. }\end{array}$} & Sch & 13 & 31 & 12 & 25 & 21 & 38 & 19 & 41 \\
\hline & We & 23 & 65 & 19 & 40 & 21 & 54 & 30 & 66 \\
\hline
\end{tabular}

$M$ - mean; SD - standard deviation; Sch - school day; We - weekend day followed by sitting (or lying) while studying, reading, playing and sitting (or lying) in front of a PC. During weekends, young people spent most of their time at a computer or in front of television. This finding applied to Czech (143 min) and Polish (157 $\mathrm{min})$ boys in particular.

\section{DISCUSSION}

For both boys and girls, the findings of increased amounts of PA at low intensity during weekends, as well as equal or increased amounts of PA at higher intensity during weekends, to some extent are surprising considering the results of previous studies $[10,11,18]$. The total daily amount of PA during school days was also greater than during weekends. One possible reason for the elimination of differences was that $93 \%$ of the weekend measurements consisted of daily PA records from Saturdays, and only $7 \%$ of records were from Sundays. Adolescents are significantly less physically active on Sundays compared with other days of the week [25]. Unfortunately, most studies have not taken into account the differences in PA on Saturdays and Sundays.

Differences between the subjective recordings and monitoring of PI were also noted. It has been confirmed that adolescents can estimate their PI better on uring school days than during weekends due to a clear schedule. On these days, the students also had a tendency to lower the estimated amount of PI. The reports of PI indicated that Czech boys spent 134 minutes (girls, 96 minutes) in front of a screen, while during weekend days this number climbed to 222 minutes (girls, 157 minutes). Polish boys, similarly to Czech boys, spent 133 minutes in front of a screen during school days (girls, 107 minutes), and this number climbed to 238 minutes on weekend days (girls, 188 minutes). On average, in both countries, boys did not meet the recommendations of the Healthy People 2010 and 2020 initiatives [26, 27] to spend less than 2 hours a day on school or weekend days in front of a screen. Girls in both countries failed to comply with these recommendations during weekends.

Strengths and limitations of the study. The main advantage of this study was the use of triangulation for PA and PI monitoring - monitoring of heart rates and PA and recording the duration of periods of PA and PI. This approach allowed the gaining of a deeper and more objective insight into PA and PI during both school and weekend days. One of the limitations was the unbalanced number of Saturday and Sunday records for PA monitoring using the accelerometers. However, recording 2 school and 2 weekend days (especially recording heart rate) is very complex and therefore extremely difficult to implement in practice. Another limitation was the ongoing issue of needing to remove the device while swimming and showering, which then only allowed the partial capture the objective activity levels reported on the subjective records of PA and PI.

\section{CONCLUSIONS}

- This study surveyed important issues related to global public health, specifically for the school environment and school settings. 
- The important and crucial relations with family were emphasized, which should increase the awareness and understanding of public health problems of this particular research sample.

- Boys and girls from both countries engaged in virtually the same amount of PA during school and weekend days and participated in more PA at lower intensities on the weekends, compared with school days.

- The importance of the inclusion of physically active school breaks into the daily school routine.

- The results indicated that less time was spent in PI, but also that the largest amount of time during the weekends was spent in front of a screen.

\section{Acknowledgments}

This paper was supported by the research grant of Czech Science Foundation (No. 13-32935S) "The objectification of comprehensive monitoring of school mental and physical strain in adolescents in the context of physical and mental condition".

\section{REFERENCES}

1. Strong WB, Malina RM, Mlimkie CJR, Daniels SR, Dishman RK, Gutin B, Hetgenroeder AC, Must A, Nixon PA, Pivarnik JM, Rowland T, Trost $\mathrm{S}$, Trudeaue F. Evidence based physical activity for school-age youth. J Pediatr. 2005; 145: 732-737.

2. Taylor AH, Cable NT, Faulkner G, Hillsdon M, Narici M, Van Der Bij AK. Physical activity and older adults: a review of health benefits and the effectiveness of interventions. J Sports Sci. 2004; 22: 703-725.

3. Warburton DER, Nicol CW, Bredin SSD. Health benefits of physical activity: the evidence. Can Med Assoc J. 2006; 174: 801-809.

4. Wolf AM, Colditz GA. Current estimates of the economic cost of obesity in the United States. Obesity Res. 2012; 6: 97-106.

5. Trudeau F, Shephard RJ. Physical education, school physical activity, school sports and academic performance. Int J Behav Nutr Phys Act. 2008; 5: 1-12.

6. Bergier J. The level of physical activity in society today - the problem of modern civilization (research overview). Hum Health. 2012; 6(1): 13-22.

7. Bartoszewicz R, Frömel K. Motor activity of junior high school students in the period of socio-economic transformations in the Poland and the Czech Republic. Human Movement. 2006; 7: 14-24.

8. Bouchard C, Shephard RJ, Stephens T. Physical activity, fitness, and health. Human Kinetics, Champaign (IL) Human Kinetics, 1994
9. Hallal PC, Victora CG, Azevedo MR, Wells JCK. Adolescent physical activity and health - A systematic review. Sports Med. 2006; 36: 1019-1030.

10. Brusseau TA, Kulinna PH, Tudor-Locke C, van der Mars H, Darst PW. Children's step counts on weekend, physical education and non-physical education days. J Human Kinetics. 2011; 27: 116-134.

11. Fairclough SJ, Ridgers ND, Welk G. Correlates of children's moderate and vigorous physical activity during weekdays and weekends. J Phys Act Health. 2012; 9: 129-137.

12. Treuth MS, Catellier DJ, Schmitz KH, Pate RR, Elder JP, McMurray RG, Blew RM, Yang S, Webber L. Weekend and weekday patterns of physical activity in overweight and normal-weight adolescent girls. Obesity. 2007; 15: 1782-1788.

13. Rowlands AV, Pilgrim EL, Eston RG. Patterns of habitus activity Gross weekdays and weekend days in 9-11-year-old children. Prev Med. 2008; 46: 317-324.

14. Davis JN, Hodges VA, Gillham MB. Physical activity compliance: differences between overweight/obese and normal-weight adults. Obesity. 2006; 14: 2259-2265.

15. Jago R, Andreson CB, Baranowski T, Watson K. Adolescent patterns of physical activity. Am J Prev Med. 2005; 28: 447-452.

16. Generelo E, Zaragoza J, Julián JA, Abarca-Sos A, Murillo B. Physical activity patterns in normal-weight adolescents on week-days and weekends. J Sports Med Phys Fitness. 2011; 51: 647-653.

17. Santos MP, Gomes H, Mota J. Physical activity and sedentary behaviors in adolescents. Ann Behav Med. 2005; 30: 21-24.

18. Bergier B, Bergier J. Paprzycki P. Level and determinants of physical activity among school adolescents in Poland. Ann Agric Environ Med. 2014; 21(1):75-78.

19. Nováková Lokvencová P, Frömel K, Chmelík F, Groffik D, Bebčáková V. School and weekend physical activity of 15-16 year old Czech, Slovak and Polish adolescents. Acta Universitatis Palackianae Olomucensis Gymnica. 2011; 41: 39-45.

20. Neuls, F. Validity and reliability of "step count" function of the actitrainer activity monitor under controlled conditions. Acta Universitatis Palackianae Olomucensis Gymnica. 2008; 38: 55-64.

21. Chytil J. Program ActiTrainer09. SoftWareCentrum: Olomouc, 2010.

22. Edwards S. Leitfaden zur Trainingskontrolle. Meyer and Meyer Verlag: Aachen, 1994.

23. Sheskin DJ. Handbook of parametric and nonparametric statistical procedures. Chapman \& Hall/CRC: Boca Raton, 2007.

24. Tolson $H$. An adjunkt to statistical signifikance: $\omega^{2}$. Res Q Exerc Sports. 1980; 51: 580-584.

25. Groffik D, Frömel K, Pelclova J. Pedometers as a method for modification of physical activity in students. J Hum Kinetics. 2008; 20: 131-137.

26. US Department of Health and Human Services. Healthy people 2010: Understanding and improving health. USDHHS, Washington, 2000.

27. US Department of Health and Human Services. Healthy people 2010: Understanding and improving health. USDHHS, Washington, 2010. 